\title{
CUARENTA AÑOS DE JURISPRUDENCIA \\ CONSTITUCIONAL EN ESPAÑA: DERECHO A \\ UN RECURSO EFECTIVO EN RELACIÓN CON LA \\ DECLARACIÓN DEL ESTADO DE ALARMA COMO \\ LIMITADORA DE DERECHOS FUNDAMENTALES
}

Forty years of Constitutional Jurisprudence in Spain:

right to an effective remedy in relation to the declaration of the State of Alarm as a limitation of fundamental rights

PEDRO TENORIO SÁNCHEZ

Universidad Nacional de Educación a Distancia

ptenorio@der.uned.es

Resumen

El presente trabajo intenta dilucidar si el ciudadano español ha dispuesto de un recurso real y efectivo para discutir la constitucionalidad o legalidad del Real Decreto $463 / 2020$, de 14 de marzo, por el que se declara el estado de alarma y los reales decretos de prórroga del estado de alarma decretado. La jurisprudencia del Tribunal Supremo y del Tribunal Constitucional podrían conducir a la imposibilidad de controlar jurídicamente la declaración del estado de alarma. Es una exigencia del Estado de derecho y del principio de recurso efectivo entender que, a la vista de la regulación del estado de alarma que realizaron el Real Decreto 463/2020 y los que acordaron la prórroga del mismo, la posible vulneración de derechos fundamentales de modo 
directo por los mencionados reales decretos hubiera sido susceptible de ser planteada en recurso de amparo ante el Tribunal Constitucional.

\section{Palabras clave}

Estado de alarma; recurso efectivo; recurso de amparo; Tribunal Constitucional; Tribunal Supremo.

\section{Abstract}

The present work seeks to ascertain if the Spanish citizen has had a real and effective remedy to question the constitutionality or legality of the Royal Decree $463 / 2020$, of March 14, by which the state of alarm was declared and the Royal Decrees that agreed to its extension. Supreme Court's and Constitutional Court's case law could lead to the inability of exerting legal control of the declaration of the state of alarm. It is a requirement of the rule of law and of the principle of the right to an effective remedy to understand that, in view of the regulation of the state of alarm carried out by Royal Decree 463/2020 and those that agreed to its extension, the possible violation of fundamental rights by the aforementioned Royal Decrees should have been susceptible of being raised in an amparo appeal before the Constitutional Court.

\section{Keywords}

State of alarm; effective remedy; amparo appeal; Constitutional Court; Supreme Court. 


\section{SUMARIO}

I. OBJETO DEL TRABAJO. II. DERECHO A UN RECURSO EFECTIVO. III. JURISPRUDENCIA DEL TRIBUNAL CONSTITUCIONAL QUE INCIDE EN EL DERECHO A UN RECURSO EFECTIVO CONTRA LA DECLARACIÓN DEL ESTADO DE ALARMA: 1. ATC 7/2012, de 13 de enero. 2. Doctrina de la STC 83/2016 sobre la naturaleza parlamentaria de la declaración. 3. ATC 40/2020, DE 30 DE ABRIL. CONCLUSIÓN. IV. RECURRIBILIDAD EN AMPARO ANTE EL TRIBUNAL CONSTITUCIONAL DE LAS DISPOSICIONES DEL GOBIERNO CON RANGO DE LEY. V. EXIGENCIAS DEL CONVENIO EUROPEO DE DERECHOS HUMANOS. VI. IMPOSIBILIDAD DE AGOTAR LA VÍA JUDICIAL PREVIA CONTRA EL REAL DECRETO 463/2020 Y DECRETOS POSTERIORES QUE LO PRORROGAN Y CARÁCTER AUTOAPLICATIVO DE LOS MISMOS: 1. Superación de la tesis negativa de la STC 83/2016. 2. Carácter no fiscalizable de las actuaciones de la Administración. 3. Proceso especial de protección de los derechos fundamentales. 4. Recurso de inconstitucionalidad y cuestión de inconstitucionalidad. VII. CONCLUSIONES. BIBLIOGRAFía.

\section{OBJETO DEL TRABAJO}

1. La aplicación del estado de alarma a la crisis sanitaria provocada por la pandemia de coronavirus ha sido criticada desde distintos puntos de vista. Algunos constitucionalistas han señalado que el estado de alarma declarado suspendía derechos y no se circunscribía a limitarlos, por lo que se ha llegado a sostener que hubiera sido más pertinente declarar el estado de excepción, ya que este permite la suspensión de determinados derechos y libertades. Varios estudios se han propuesto precisar los conceptos de suspensión y limitación (Escobar Roca, 2021) o a intentar la superación de estos conceptos como criterio para decidir la constitucionalidad de la declaración del estado de alarma (Gómez Fernández, 2021).

Distinto punto de vista es el de autores como Muñoz Machado, para quien lo que sobra es la declaración de estado de alarma, ya que la legislación sanitaria ya permite suspender derechos (Muñoz Machado, 2020: 114), de manera parecida a lo que sostuvieron, en relación con el estado de alarma de 2010, Vidal Prado y Delgado Ramos (2011: 263) y Aba Catoira 
(2011: 335-339). Siguiendo con la crisis sanitaria provocada por el COVID, Muñoz Machado considera que la fusión del régimen del estado de alarma y lo establecido en la legislación sanitaria para la lucha contra las epidemias y crisis sanitarias, ya previsto en la Ley Orgánica 4/1981, de 1 de junio, carece de tradición en nuestro ordenamiento jurídico y genera confusión y alteraciones indebidas del reparto de competencias entre los poderes territoriales. Añade que la legislación sanitaria española, antes y después de aprobada la Constitución, atribuye poderes suficientes para luchar contra la pandemia. La declaración de estado de alarma no habría añadido habilitaciones imprescindibles. Las acciones para combatir la epidemia - siempre según el autor- pueden consistir en medidas de restricción de las libertades, de acuerdo con la legislación sanitaria, debidamente motivadas y justificadas en la necesidad.

2. En el presente trabajo vamos a intentar dilucidar si el ciudadano en nuestro país ha dispuesto de un recurso real y efectivo para discutir la constitucionalidad o legalidad del Real Decreto 463/2020, de 14 de marzo, por el que se declara el estado de alarma para la gestión de la situación de crisis sanitaria ocasionada por el COVID-19 y de los Reales Decretos 476/2020, de 27 de marzo, 487/2020, de 10 de abril, 492/2020, de 24 de abril, 514/2020, de 8 de mayo, 537/2020, de 22 de mayo, y 555/2020, de 5 de junio, que acordaron la prórroga del estado de alarma decretado. Acotar el objeto de este trabajo resulta imprescindible, si tenemos en cuenta que a finales del año 2020 las normas dictadas con ocasión de la pandemia ocupaban ya más de 3.000 páginas del Boletín Oficial del Estado (Muñoz Machado, 2020: 127), a lo que se añaden las dudas doctrinales respecto de la idoneidad del estado de alarma para afrontar supuestos de alteración política o de perturbación de la paz social (Lafuente Balle, 1989: 31).

3. Concretamente, vamos a centrarnos en el art. 7 del Real Decreto $463 / 2020$, el cual dispuso que, durante la vigencia del estado de alarma, «las personas únicamente podrán circular por las vías o espacios de uso público para la realización de las siguientes actividades: [...]». Dichas actividades se concretaban en la adquisición de alimentos, productos farmacéuticos y de primera necesidad; asistencia a centros, servicios y establecimientos sanitarios; desplazamiento al lugar de trabajo para efectuar su prestación laboral, profesional o empresarial; retorno al lugar de residencia habitual; asistencia y cuidado a mayores, menores, dependientes, personas con discapacidad o personas especialmente vulnerables; desplazamiento a entidades financieras y de seguros; aquellas que tuvieran por causa fuerza mayor o situación de necesidad; y finalmente cualquier otra actividad de análoga naturaleza. Asimismo, se permitía «la circulación de vehículos particulares por las vías de uso público para la realización de las actividades referidas en el apartado 
anterior o para el repostaje en gasolineras o estaciones de servicio». Cualquier otra actividad se encontraba prohibida.

4. De esta manera, algunos constitucionalistas han sostenido que el estado de alarma suspende o elimina derechos fundamentales, como son la libre circulación y la libertad de residencia reconocidos en el art. 19 CE y el derecho de reunión, recogido en el art. $21 \mathrm{CE}$, pues las personas quedaban obligadas a confinarse en su domicilio sin poder circular libremente ni poder cambiar de residencia y además al prohibir circular no solamente en determinados lugares y a determinadas horas, se prohibía también reunirse con otras personas. Se ha considerado que esto suponía una suspensión de los derechos de circulación y de reunión. Incluso se ha señalado que el confinamiento puede afectar a la libertad personal del art. 17 CE (Cotino Hueso, 2021).

Desde esta perspectiva, se ha señalado que ni la Constitución ni la Ley Orgánica 9/1983 (en particular el art. 10 de esta última) mencionan las razones de salud como causa de suspensión del derecho de reunión o como causa para limitar el derecho de libre circulación. A primera vista, el art. 7 del Real Decreto 467/2020, al suspender de modo directo los derechos de libre circulación y residencia y de reunión, entra en contradicción con el art. 55 de la Constitución (Díaz Revorio, 2021) y con el art. 11, apdo. a), de la Ley Orgánica 4/1981 reguladora de los estados de alarma, excepción y sitio. Al no establecerse como excepción a la prohibición general de libre circulación los desplazamientos necesarios para el derecho de reunión y manifestación, estos últimos derechos han quedado también afectados. Y ni la Constitución y ni la Ley Orgánica 4/1981 proporcionan base para semejante suspensión de derechos. Como carece de fundamento constitucional y legal establecer que la jurisdicción contencioso-administrativa tenga que autorizar previamente fuera de los casos previstos en la Constitución y las leyes, medidas de la administración sanitaria que restrinjan derechos individuales (Muñoz Machado, 2020: 128), autorizaciones que desbordan la división constitucional de poderes.

5. Pero no es el objeto de este trabajo discutir la posible contradicción del estado de alarma (cuya regulación ha sido por lo demás criticada por la doctrina —Cruz Villalón, 1984: 60 y 80; Torres Muro, 2009: 1815-) declarado por el RD 467/2020 con los arts. 19 y 21 de la Constitución, sino (repetimos) tan solo dilucidar si, en caso de que un ciudadano así se lo planteara, disponía de un recurso efectivo en nuestro ordenamiento para la defensa de sus derechos fundamentales recogidos en la Constitución y de los reconocidos en el CEDH.

6. En nuestra opinión, en principio, el real decreto de declaración del estado de alarma es una disposición del Gobierno de carácter general, contra la que cabe recurso ante el orden jurisdiccional contencioso-adminis- 
trativo (Rodríguez Oliver, 1981: 2316-2318; Cruz Villalón, 1981: 115-116; Lafuente Balle, 1990: 34, 42) que puede ser directo (en la medida en que incluya preceptos autoaplicativos) e indirecto (es decir, dirigido contra los actos aplicativos, pero fundamentado en la ilegalidad o en la inconstitucionalidad del decreto). Y contra la eventual inadmisión o desestimación del recurso contencioso administrativo cabe recurso de amparo.

7. Sin embargo, la jurisprudencia del Tribunal Supremo y del Tribunal Constitucional, como veremos, podrían conducir a la imposibilidad de controlar jurídicamente la declaración del estado de alarma. Obviamente, el principio conforme al cual nuestro Estado es un Estado de derecho y el derecho a un recurso efectivo cierran el paso a una lectura de esa jurisprudencia que produzca ese resultado y, si tal interpretación no fuera factible, se evidenciaría la necesidad de matizarlas o rectificarlas. Vamos a desarrollar este conjunto de ideas a lo largo del trabajo.

\section{DERECHO A UN RECURSO EFECTIVO}

1. Comencemos por referirnos al derecho a un recurso efectivo que, como hemos anunciado, debe orientar nuestra interpretación de la ley y de la jurisprudencia acerca del tema.

2. Como sabemos, son muchas las ocasiones en que nuestro Tribunal Constitucional (por ejemplo, en la STC 87/2020, de 20 de julio, FJ 3 B) ha insistido en la necesidad de tener en especial consideración al CEDH y a la jurisprudencia del TEDH para la interpretación de las normas relativas a los derechos fundamentales y libertades reconocidos por la Constitución, como exige el art 10.2 CE con referencia en general a los tratados y acuerdos internacionales de derechos humanos ratificados por España. La relevancia de los medios internos establecidos para la protección de los derechos reconocidos es reconocida en el CEDH. En efecto, el art. 1 del CEDH establece la obligación de los Estados de reconocer (en la versión francesa) o de asegurar (en la versión inglesa) los derechos y libertades protegidos por el CEDH. Parte de esta obligación es la posibilidad de acceder a recursos internos para la defensa de estos derechos. Más concretamente, el art. $13 \mathrm{CEDH}$ exige que estén previstos en los ordenamientos internos recursos efectivos. Dice el art. $13 \mathrm{CEDH}$ que «toda persona cuyos derechos y libertades reconocidos en el presente Convenio hayan sido violados tiene el derecho a la concesión de un recurso efectivo ante una instancia nacional, incluso cuando la violación haya sido cometida por personas que actúen en el ejercicio de sus funciones oficiales». 
3. Ciertamente, el TEDH ha matizado que la eficacia de un remedio en el sentido del art. $13 \mathrm{CEDH}$ no consiste en la certeza de un resultado favorable al reclamante (STEDH, Sección quinta, de 20 de enero de 2011, caso Payet c. Francia, apdo. 127). Pero la eficacia de los recursos exigidos por el art. $13 \mathrm{CEDH}$ supone que tales recursos puedan impedir la ejecución de medidas que sean contrarias al Convenio y cuyas consecuencias sean potencialmente irreversibles (esto se puede deducir de la STEDH Jabari c. Turquía, número 40.035/98, parágrafo 50, CEDH 2000, VIII, parágrafo 50). Por ello, resulta necesario determinar si los medios de que dispone un recurrente en un Estado miembro del Convenio para denunciar la falta de habilitación o la desproporción de las limitaciones a su libertad pueden o no ser calificadas como eficaces, en el sentido de que podían haber impedido que se produjera o continuara la posible violación o si podían haber facilitado al demandante un recurso adecuado para cualquier violación que ya se hubiera producido (STEDH caso Payet c. Francia, apdo. 130).

\section{JURISPRUDENCIA DEL TRIBUNAL CONSTITUCIONAL QUE INCIDE EN EL DERECHO A UN RECURSO EFECTIVO CONTRA LA DECLARACIÓN DEL ESTADO DE ALARMA}

1. Vamos a referirnos a continuación a la jurisprudencia del Tribunal Constitucional relacionada con el estado de alarma, señalando desde ahora que una interpretación de la misma no ceñida a la ratio decidendi de sus resoluciones podría dificultar el reconocimiento de que cabe recurso de amparo contra la declaración del estado de alarma.

2. La jurisprudencia del Tribunal Constitucional acerca de los estados de alarma es escasa. Es comprensible que así sea, si tenemos en cuenta que desde que se aprobó la Constitución hemos disfrutado de normalidad constitucional hasta 2010 (Cruz, 2004: 187) y solamente se han declarado cuatro estados de alarma, tres de los cuales han sido recientes. Concretamente, se han declarado los estados de alarma mediante los siguientes reales decretos: Real Decreto 1673/2010, de 4 de diciembre (que, como señalaron en su día Vidal Prado y Delgado Ramos, 2011: 204, sentó mal precedente); Real Decreto 463/2020, de 14 de marzo, Real Decreto 900/2020, de 9 de octubre y Real Decreto 926/2020, de 25 de octubre.

3. Debe añadirse que en el primero de los estados de alarma referidos no se impugnó el real decreto, sino el acuerdo del Pleno del Congreso de los Diputados de 16 de diciembre de 2010, de autorización de la prórroga de dicho estado de alarma, (impugnación que dio lugar al ATC 7/2012, de 13 de enero, del Pleno) así como el Auto de la Sala de lo Contencioso-ad- 
ministrativo del Tribunal Supremo, de 30 de mayo de 2011, que había sido confirmado en reposición por Auto de 1 de junio de 2012, por el que se había declarado la inadmisión del recurso contencioso administrativo interpuesto por 327 controladores aéreos contra el mencionado Real Decreto 1673/2010, impugnación que dio lugar a la STC 83/2016, de 28 de abril, de Pleno.

\section{ATC $7 / 2012$, DE 13 DE ENERO}

1. Entrando ya en el ATC 7/2012, de 13 de enero, debemos subrayar que resolvía un recurso que tenía por objeto decisiones o actos que procedían de las Cortes Generales o de las asambleas legislativas de las comunidades autónomas, es decir, un recurso de amparo interpuesto por la vía del art. 42 LOTC. Según el referido precepto, «las decisiones o actos sin valor de ley, emanados de las Cortes o de cualquiera de sus órganos, o de las Asambleas Legislativas de las Comunidades Autónomas, o de sus órganos, que violen los derechos y libertades susceptibles de amparo constitucional, podrán ser recurridos dentro del plazo de tres meses desde que, con arreglo a las normas internas de las Cámaras o Asambleas, sean firmes».

El recurso tenía por objeto el Acuerdo del Pleno del Congreso de los Diputados de 16 de diciembre de 2010, de autorización de la prórroga del estado de alarma. El ATC 7/2012 afirmó que quedaba excluida la utilización de la vía procesal del recurso de amparo (es decir, de la vía del art. 42 LOTC) contra decisiones o actos de las cámaras legislativas o de cualquiera de sus órganos que tengan valor de ley. Esta exclusión se basaba en el tenor literal del repetido art. 42, que hacía referencia a decisiones y actos de las Cortes o de cualquiera de sus órganos, o de las asambleas legislativas de las comunidades autónomas, o de sus órganos «sin valor de ley». Y se consideraba que se había "declarado que ésta clara exclusión que resulta del art. 42 LOTC 'es respecto a las disposiciones con fuerza y valor de ley susceptibles de ser objeto de recurso de inconstitucionalidad de acuerdo con el art. 161.1 a) de la Constitución y al art. 27 de la misma Ley Orgánica', destacando la conexión existente entre los referidos preceptos (SSTC 118/1988, de 20 de junio, FJ 3; y 121/1997, de 1 de julio, FJ 5)».

2. Aquel ATC tenía como presupuesto la idea de que el art. 42 LOTC únicamente permitía la impugnación de decisiones y actos sin valor de ley que fueran de naturaleza típicamente parlamentaria. Era claro que el acuerdo recurrido tenía naturaleza parlamentaria. El Tribunal Constitucional calificó como evidente esta naturaleza parlamentaria. Pero fue discutido en el Pleno si el acuerdo tenía o no «valor de ley» a los efectos de quedar excluido del art. 42 LOTC. El auto le atribuyó valor de ley, afirmando que «el acuerdo del Pleno del Congreso de los Diputados de 16 de diciembre de 2010, de autorización 
de la prórroga del estado de alarma declarado por el Real Decreto 1673/2010, de 4 de diciembre, en tanto que no subsumible en la categoría de decisiones o actos sin valor de ley no es susceptible de ser impugnado a través del recurso de amparo previsto en el art. 42 LOTC». No obstante, tres magistrados firmaron un voto particular que disentía de la atribución de tal naturaleza al acuerdo.

3. Destaquemos que el ATC 7/2012 se pronunció acerca de si el acuerdo de autorización de la prórroga del estado de alarma adoptado por el Pleno del Congreso de los Diputados era o no un acto de naturaleza parlamentaria sin valor de ley y por tanto impugnable por la vía de la 42, pero no abordó, por tanto, un recurso de amparo interpuesto contra «disposiciones, actos jurídicos, omisiones o simple vía de hecho del gobierno o de sus autoridades o funcionarios", es decir, no recayó sobre un recurso de amparo del art. 43 LOTC. El ATC 7/2012 lo que decidió era si el acuerdo del Pleno del Congreso de los Diputados, no del Gobierno, tenía o no valor de ley y en consecuencia si, dado el tenor literal del art. 42, era o no recurrible.

\section{DOCTRINA DE LA STC $83 / 2016$ SOBRE LA NATURALEZA PARLAMENTARIA DE LA DECLARACIÓN}

1. También debemos analizar cuidadosamente el objeto de la STC 83/2016, de 28 de abril, del Pleno, para examinar si cabe entender que generó jurisprudencia aplicable al derecho a un recurso efectivo frente a la declaración del estado de alarma.

La STC 83/2016, de 28 de abril, tuvo por objeto, desde la perspectiva de una eventual vulneración del derecho a la tutela judicial efectiva (en concreto, desde la perspectiva del acceso a la jurisdicción), el Auto de 30 de mayo de 2011 de la Sección Séptima de la Sala de lo contencioso-administrativo del Tribunal Supremo que había inadmitido el recurso contencioso administrativo interpuesto por 327 personas contra tres resoluciones: el Real Decreto $1673 / 2010$, de 4 de diciembre, por el que se declaraba el estado de alarma para la normalización del servicio público esencial del transporte aéreo; el Acuerdo del Consejo de Ministros de 14 de diciembre de 2010, por el que se solicitaba del Congreso de los Diputados autorización para prorrogar en sus propios términos el estado de alarma; y en tercer lugar el Real Decreto 1717/2010, de 17 de diciembre, por el que se prorroga el estado de alarma declarado por el Real Decreto 1673/2010, de 4 de diciembre.

Aunque el objeto señalado por los recursos eran resoluciones del Consejo de Ministros, el Tribunal Supremo basó la inadmisión del recurso contencioso administrativo en la naturaleza y carácter parlamentario que la autorización de prórroga había atribuido al Real Decreto 1673/2010, que había declarado el estado de alarma. Como quiera que el Congreso había autorizado la prórroga 
del estado de alarma en los mismos términos en los que había sido inicialmente declarado, el Tribunal Supremo entendió que el Congreso había asumido íntegramente «el contenido de su inicial declaración por el Real Decreto 1673/2010», con lo que había conferido a dicha declaración «naturaleza y carácter parlamentario».

Partiendo de esta consideración, el Tribunal Supremo va a excluir el objeto del proceso de la jurisdicción ordinaria: «[...] no tratándose ya de una acción gubernamental sino de una resolución de la cámara, el Real Decreto queda fuera del ámbito que el artículo 106.1 de la Constitución delimita para el control judicial de la acción administrativa y deja de tener encaje los artículos 1 y 2 de la Ley reguladora». El Tribunal Supremo no entró a calificar el rango normativo del real decreto, simplemente, partiendo de la naturaleza parlamentaria del mismo, lo consideró excluido de la jurisdicción contencioso-administrativa. (Es, sin embargo, discutible que la naturaleza parlamentaria del decreto de prórroga pueda modificar con efectos retroactivos la naturaleza gubernamental del previo decreto de declaración de estado de prórroga. No se entiende cómo la prórroga puede definir la naturaleza de lo prorrogado. Más bien parece que la naturaleza parlamentaria del decreto de prórroga no puede vaciar la competencia del Tribunal Supremo sobre el decreto de declaración del estado de alarma.)

Sea como fuere, los recurrentes cuestionaron la argumentación del Tribunal Supremo. Sostuvieron ante el Tribunal Constitucional que la intervención prevista del Congreso de los Diputados no podía modificar la verdadera naturaleza jurídica de los decretos por los que se había declarado y se había prorrogado el estado de alarma. Para los recurrentes se trataba de disposiciones y actos de carácter general procedentes de la Administración, fiscalizables por la jurisdicción contencioso-administrativa de acuerdo con los arts. 12.1 a) de la Ley de jurisdicción contencioso-administrativa y art 3.1 de la Ley Orgánica 4/1981. Ante el Tribunal Constitucional, los recurrentes pusieron de manifiesto que habían impugnado ante la jurisdicción contencioso-administrativa disposiciones del Gobierno, no actos de naturaleza parlamentaria.

2. El Tribunal Constitucional confirmó la resolución adoptada por el Tribunal Supremo, si bien se apartó de este último tribunal en cuanto a la fundamentación de su decisión. En efecto, en el antecedente 3, letra c de la STC 83/2016, se dice que no es objeto del recurso de amparo la posible inconstitucionalidad o ilegalidad de los Reales Decretos 1673/2010 y 1717/2010 y del Acuerdo del Consejo de Ministros de 14 de diciembre de 2010, es decir, que no se sitúa al Tribunal Constitucional ante un recurso de amparo de los regulados por el art. 43 LOTC, sino que el recurso de amparo utilizaba la vía del art. 44 LOTC, pues se dirigía contra la vulneración que los recurrentes 
atribuían a la resolución del Tribunal Supremo. Como es sabido, el art. 44.1 LOTC establece que «las violaciones de los derechos y libertades susceptibles de amparo constitucional, que tuvieran su origen inmediato y directo en un acto u omisión de un órgano judicial, podrán dar lugar a este recurso siempre que se cumplan los requisitos siguientes: $[\ldots]$ »

Pues bien, la STC 83/2016, recuperando la perspectiva del ATC 7/2012, orienta su decisión (Villar Crespo, 2018: 31) no planteándose la naturaleza parlamentaria o no del Real Decreto 1673/2010 que había declarado el estado de alarma (lo que había sido el fundamento de la inadmisión por parte del Tribunal Supremo del recurso), sino en el rango normativo del decreto que formaliza el estado de alarma. La STC 83/2016 sostendrá (de manera parecida a algunos autores: García Cuadrado, 1999: 63; Navas Castillo, 1997: 155) que el real decreto que declara el estado de alarma queda revestido «de un valor normativo equiparable, por su contenido y efectos, al de las leyes y normas asimilables cuya aplicación puede excepcionar, suspender o modificar durante el estado de alarma", toda vez que "sus previsiones habilitan los efectos jurídicos [...] sobre la legislación en vigor antes de la declaración, incluidas las normas con rango de ley». Partiendo de ese rango de ley, la STC 83/2016 afirmará que «las resoluciones judiciales impugnadas, que inadmitieron el recurso contencioso-administrativo interpuesto por los demandantes de amparo contra los Reales Decretos 1673/2010, de 4 de diciembre y 1717/2010, de 17 de diciembre, no han vulnerado su derecho a la tutela judicial efectiva en su vertiente de derecho de acceso a la jurisdicción (art. 24.1 CE), al resultar aquellos excluidos, en razón de su valor o rango de ley, del ámbito de fiscalización del orden jurisdiccional contencioso-administrativo (arts. $106 \mathrm{CE}$ y 1 LJCA, contrario sensu)».

3. La STC 83/2016 podía haberse quedado ahí, y no hacer mayores afirmaciones generales acerca del control de las declaraciones del estado de alarma, ya que con estas consideraciones que hemos visto estaba resuelto el objeto del proceso. Sin embargo, la referida STC 83/2016, en el párrafo segundo del FJ 11, dirá que los reales decretos mencionados «solo cabe impugnarlos, de acuerdo con el modelo de jurisdicción de nuestro ordenamiento jurídico, ante este Tribunal Constitucional a través de los procesos constitucionales previstos en la Constitución y en la Ley Orgánica del Tribunal Constitucional, que tienen por objeto el control de constitucionalidad de las leyes, disposiciones y actos con fuerza o valor de ley [arts. 161 y $163 \mathrm{CE}, 27.2$ b) LOTC]».

4. A partir de esta afirmación, por más que se trate de un obiter dictum, pues no se integra en la ratio decidendi de la sentencia, cabría sostener que no cabe recurso de amparo frente a los reales decretos que declaren el estado de alarma y sus prórrogas. Sin embargo, esta interpretación de la Sentencia 
83/2016 sería contraria al tenor literal del art. 43 LOTC, a la naturaleza del recurso de amparo y en última instancia a la doctrina del Tribunal Constitucional, toda vez que se trata de una afirmación que, como se ha indicado, se apoya en un obiter dictum, en un pasaje que no crea jurisprudencia.

\section{ATC 40/2020, DE 30 DE ABRIL. CONCLUSIÓN}

El ATC 40/2020, de 30 de abril, inadmitió un recurso de amparo contra una resolución de la Subdelegación del Gobierno de Pontevedra que no permitió una manifestación que pretendía convocar determinado sindicato, así como contra la resolución del Tribunal Superior de Justicia de Galicia que había confirmado la resolución administrativa. El auto, del que se ha dicho que casi parece una sentencia desestimatoria (Presno Linera, 2021: 17), y que ha sido objeto de una fundamentada crítica (Arnaldo Alcubilla, 2020) se centra sobre todo en el derecho de manifestación y expresamente evita pronunciarse acerca del RD que había declarado el estado de alarma: «La discusión sobre si el decreto de declaración del estado de alarma supone o no, de facto, y por derivación de la limitación de la libertad deambulatoria del art. $19 \mathrm{CE}$, una limitación excesiva o incluso una suspensión del derecho de manifestación no puede ser abordada, ni siquiera a efectos dialécticos en este momento procesal, ni siquiera en este recurso de amparo». Y ello porque de lo que se trata no es de tal RD, sino de «la interpretación del alcance de tal mecanismo de excepcionalidad por parte de la administración y después por parte del propio Tribunal que refrenda tal prohibición» (FJ 3).

2. Es sostenible, por todo ello, que no existe jurisprudencia constitucional acerca de la recurribilidad en amparo de la declaración del estado de alarma si tenemos en cuenta que la afirmación que hemos visto del FJ 11 de la STC 83/2016 no se integra en la ratio decidendi de la sentencia. No hay ninguna sentencia ni auto del Tribunal Constitucional que haya afrontado una demanda de amparo interpuesta contra el real decreto que declara el estado de alarma. Recuérdese que el ATC 7/2012 lo que excluyó fue que el art. 42 LOTC estableciera la posibilidad de interponer recurso de amparo frente a un acuerdo del Parlamento por el que se autorizaba la prórroga del estado de alarma, basándose en que se trataba de una disposición de naturaleza parlamentaria y con valor de ley. Por lo que se refiere a la STC 83/2016, insistamos que lo que desestimó fue la pretendida vulneración del acceso a la justicia de una decisión del Tribunal Supremo (recurso por la vía del art. 44 LOTC) de no controlar reales decretos por los que se acordaba el estado de alarma y sus prórrogas al considerar que desbordaban el ámbito que delimita su jurisdicción. 


\section{RECURRIBILIDAD EN AMPARO ANTE EL TRIBUNAL CONSTITUCIONAL DE LAS DISPOSICIONES DEL GOBIERNO CON RANGO DE LEY}

1. Cabe preguntarse si la STC 83/2016, en el pasaje del FJ 11 al que hemos aludido, pretende excluir el recurso de amparo como mecanismo para el control de los reales decretos del estado de alarma, aunque, literalmente, no es eso lo que dice. Pues bien, en todo caso, entendemos que cabe recurso de amparo frente a las disposiciones generales del Gobierno con rango de ley en el caso de que sean autoaplicativas. Detengámonos en esta cuestión.

2. Es discutido si cabe o no el recurso de amparo contra leyes. Nosotros vamos a realizar al respecto un apunte sobre jurisprudencia constitucional que explique la que consideramos que es la postura del Tribunal Constitucional.

La referencia jurisprudencial más reciente que hemos encontrado sobre la cuestión es la STC 155/2009, de 25 de junio, FJ 2, es decir la importante sentencia en que nuestro Tribunal Constitucional desarrolla sus criterios para determinar si un recurso de amparo tiene o no "especial trascendencia constitucional». Nuestro Tribunal Constitucional considera como supuesto de concurrencia de tal requisito de admisión: «c) o cuando la vulneración del derecho fundamental que se denuncia provenga de la ley o de otra disposición de carácter general». Así pues, se desprende que no solo cabe amparo contra leyes, sino que además tales recursos de amparo tienen especial trascendencia constitucional.

Ahora bien, consideramos que el sentido de esa afirmación debe integrarse con los términos en que nuestro Tribunal Constitucional viene entendiendo esta figura desde la STC 41/1981, de 18 de diciembre, FJ 1. Allí se dijo: «De este modo, puede admitirse una pretensión directa de inconstitucionalidad sostenida por particulares, aunque limitada a las leyes que lesionen o coarten los derechos y libertades reconocidos en los arts. 14 al 30 de la Constitución y a los casos en que el recurrente haya experimentado una lesión concreta y actual en sus derechos y siempre que sean inescindibles el amparo constitucional y la inconstitucionalidad de la Ley.»

Se trataba, en el caso, de determinados supuestos de ejecución hipotecaria. Los demandantes de amparo sostenían que las ejecuciones practicadas se ajustaban a la ley, pero entendían que esta última era inconstitucional. El Tribunal considera admisible un recurso de amparo de esta naturaleza, si bien entiende que en el proceso de amparo no podrá fallarse la inconstitucionalidad de la ley, lo que sólo podrá ocurrir si la Sala plantea al Pleno la llamada «auto-cuestión de inconstitucionalidad» del art. 55.2 LOTC. Hasta donde hemos alcanzado a ver, esto es lo que permite nuestro Tribunal Constitucional, si bien en la STC 41/1981 califica esto como una pretensión directa 
de inconstitucionalidad y en cambio en otros casos, con cita de la STC 41/1981, califica tal recurso como indirecto. En este sentido, puede verse la STC 90/1995, de 9 de junio, FJ 3:

«3. Como ya dijimos en la STC 41/1981, pese a la redacción del art. 41.3 LOTC, y en virtud de lo dispuesto en el art. 55.2 LOTC, en el recurso de amparo es admisible que los particulares puedan plantear una pretensión indirecta de inconstitucionalidad, cuando se dirija contra una ley que lesione uno de los derechos reconocidos en los arts. 14 a $30 \mathrm{CE}$, en los casos en los que el recurrente haya experimentado una lesión concreta y actual en sus derechos fundamentales, siempre que sean inescindibles el amparo constitucional y la inconstitucionalidad de la ley cuya aplicación determina la vulneración del derecho fundamental.» (Previamente, en el FJ 2, la STC 90/1995 explica que «si bien el recurso se dirige formalmente contra la mencionada Sentencia de la Audiencia Provincial de Oviedo, en realidad lo que el recurrente cuestiona es la conformidad con la Constitución del art. 64 L.A.U. y, en concreto, con el derecho que garantiza el art. 14 de la Norma fundamental».)

También puede verse la posterior STC 209/1998, acerca de una liquidación de la Administración de 1983, sobre IRPF de 1980. En el recurso de amparo, dirigido contra una liquidación impositiva, se cuestiona «indirectamente» la Ley 44/1978 del IRPF. El Tribunal Constitucional estima el recurso de amparo. La consecuencia es la inaplicación de la Ley 44/1978 por ser contraria a la Constitución. En ella se cita la STC 41/1981.

$\mathrm{Si}$ empleamos las nociones de recurso directo e indirecto de manera análoga a como usa estas denominaciones la doctrina y jurisprudencia en el ámbito del derecho administrativo - cuando habla de recurso directo e indirecto contra los Reglamentos-, diríamos que la impugnación de leyes o actos con fuerza de Ley por vía indirecta es admisible y ha venido siendo admitida por nuestro Tribunal Constitucional de modo constante a partir de la STC 41/1981 (FJ 1).

Sin embargo, no sucede lo mismo con la impugnación directa, esto es, la que tendría por objeto una norma legal. El art. 42 de la LOTC, a contrario, excluye, en principio, del amparo los actos con valor de Ley emanados de las Cortes o de las asambleas legislativas de las comunidades autónomas. Así lo ha declarado en diversas resoluciones nuestro Tribunal Constitucional (AATC 183/1984, 206/1986, y 244/1986 y SSTC 206/1990, FJ 5; 119/1991, FJ 4; 31/1994, FJ 4; y 88/1995, FJ 5, in fine).

3. Esto apuntado en cuanto al amparo contra leyes, refirámonos ahora a las disposiciones del Gobierno, al margen de que tengan o no rango de ley.

$\mathrm{El}$ art. 43 LOTC dice que las violaciones de los derechos fundamentales protegidos por recurso de amparo ante el Tribunal Constitucional, causadas por disposiciones del Gobierno, podrán dar lugar a recurso de amparo una 
vez que se haya agotado la vía judicial procedente. Esto es así, sin excluir las normas con rango de ley. A diferencia del art. 42 LOTC, nada dice el art. 43 LOTC del rango de las normas. Y la omisión del art. 43 LOTC no cabe atribuirla a un olvido del legislador, pues ambos preceptos son sucesivos y era evidente para el legislador constitucional que el Gobierno podía dictar normas con rango de ley, como se deriva de los arts. 82 a 85 y 86 de la Constitución, donde se regulan los decretos legislativos y los decretos leyes.

La viabilidad del recurso de amparo directo contra una norma procedente del Gobierno guarda relación con la posibilidad o imposibilidad de agotar la vía judicial previa. Si no es posible acudir a la jurisdicción contencioso-administrativa para impugnar una disposición del Gobierno, la disposición será impugnable mediante recurso de amparo ante el Tribunal Constitucional con independencia del rango de aquella, en aplicación del principio según el cual no deben existir ámbitos de la actuación del Ejecutivo exentos de control judicial, y el principio de control efectivo o tutela real de los derechos fundamentales, que en la actualidad, además de ser una exigencia del Estado de derecho, se deriva de la regla según la cual los derechos fundamentales han de ser protegidos por recurso interno efectivo, regla recogida por el Convenio Europeo de Derechos Humanos, como hemos visto al comienzo de este trabajo (epígrafe 2).

4. Aun aceptando, tras la STC 83/2016, que los reales decretos que declaran el estado de alarma tengan rango de ley, ello no obstaría para que sean recurribles en amparo ante el Tribunal Constitucional. La doctrina general aplicable a los reglamentos en cuanto normas generales, según la cual solo pueden generar lesión a particulares a través de los actos de aplicación, se puede trasladar a este ámbito. Cuando las disposiciones del Gobierno son «autoaplicativas», esto es, cuando pueden irrogar una lesión de un derecho fundamental sin necesidad de que medien actos de aplicación, podemos derivar de la jurisprudencia del Tribunal Constitucional que cabe la impugnación directa de los mismos. En este sentido, Pérez Tremps (Requejo Pagés, 2001: 650) dice que esto es viable, porque en la única ocasión en que este tema se ha planteado en una resolución del Tribunal Constitucional, este último no excluyó la posibilidad de impugnación directa, si bien en aquel caso entendió que la norma impugnada no era autoaplicativa. Se trata del ATC 291/1997, de 22 de julio, en el que se resolvió acerca de un recurso de amparo planteado directamente contra determinados preceptos de un decreto ley (la disposición adicional única y los arts. 1.2 y 3 del Real Decreto-Ley 1/1997, de 31 de enero', y en el que se dijo que: «[...] en el ámbito del recurso de amparo [...] podrá procederse al enjuiciamiento de normas cuando por su mera existencia o entrada en vigor se cause la lesión concreta y actual del derecho fundamental (STC 167/1987, fundamento jurídico 2)» (ATC 291/1997, FJ 2).

Efectivamente, el ATC 291/1997, de 22 de julio, dice que son recurribles directamente en amparo las disposiciones de Gobierno que a pesar de su rango 
de ley y de su valor normativo vulneren derechos fundamentales, cuando no sea posible frente a su aplicación inmediata, agotar una vía judicial previa ocluida (ATC 291/1997, FJ 2). El auto argumenta de manera consecuencialista. En efecto, dice que sostener lo contrario llevaría a que «una ilegítima injerencia del Gobierno en los derechos fundamentales de un particular [estuviera] exenta de toda posibilidad de amparo, pues ni podría acudirse a la jurisdicción ordinaria ni a la constitucional» (ATC 291/1997, FJ 2). En alguna medida, el carácter «autoaplicativo» de la norma viene a asociarse con la oclusión de la vía judicial previa. En tal sentido, no sería decisivo el rango de la norma.

Así cabe desprenderlo, del mismo modo, de la STC 220/1991, de 25 de noviembre, que también subraya la imposibilidad de agotar la vía judicial como presupuesto determinante de la interposición directa del recurso de amparo contra la negativa del Gobierno vasco a facilitar la información solicitada por parlamentarios vascos. Remitimos al FJ 2.

5. En suma, de la interpretación de los arts. 42 y 43 de la LOTC, de la calificación de nuestro Estado como Estado de derecho, de la exigencia de que los recursos internos para la protección de los derechos fundamentales sean efectivos (como establece el CEDH) y de la propia jurisprudencia del Tribunal Constitucional podemos derivar que frente a una declaración del estado de alarma cabe recurso de amparo ante el Tribunal Constitucional en aquellos extremos o puntos en que la declaración resulte autoaplicativa. Así se desprende del ATC 291/1997, FJ 2, y de la STC 220/1991, de 25 de noviembre, resultando desde nuestra perspectiva la afirmación de la STC 83/2016, FJ 11, un obiter dictum que, además, interpretado literalmente, no es contradictorio con este entendimiento.

\section{EXIGENCIAS DEL CONVENIO EUROPEO DE DERECHOS HUMANOS}

1. Es frecuente entre los estudiosos de los estados excepcionales señalar el peligro del vaciamiento del Estado de derecho (Goig, 2009b: 251). Y también destacan que la legislación de excepción establece el principio de que la declaración de los estados excepcionales no interrumpe el normal funcionamiento de los poderes constitucionales del Estado (Fernández Segado, 1981: 90). Pues bien, la situación generada por la jurisprudencia del Tribunal Constitucional y por el Tribunal Supremo resulta contraria a las exigencias del Estado de derecho y al principio de recurso efectivo, salvo que se acepte que cabe recurso directo ante el Tribunal Constitucional. Para constatarlo, comencemos por referirnos a las exigencias del $\mathrm{CEDH}$. 
2. Por lo que se refiere a las exigencias del CEDH, concretamente, de los arts. 6.1 y 13 , que son parámetro interpretativo de nuestros derechos fundamentales (por exigencia del art. 10.2 CE), las limitaciones de la admisión del recurso de amparo pueden ser compatibles con el Convenio, pero no pueden llegar al punto de desconocer la sustancia y finalidad del recurso, de incurrir en un formalismo que ni siquiera está amparado por la regulación literal del mismo. En este sentido, se puede traer a colación la STEDH de 22 de septiembre de 2009, asunto Ferré Gisbert c. España, apdos. 27 y 28, que, en relación con un recurso de amparo inadmitido por incumplimiento del plazo procesal, dijo que:

[...] el «derecho a un Tribunal» del que el derecho de acceso constituye un aspecto (ver, principalmente, Golder c. Reino Unido, de 21 de febrero de 1975 [TEDH 1971, 1], ap. 36, serie A núm. 18) no es absoluto y se presta a limitaciones implícitamente admitidas, principalmente en lo que concierne a las condiciones de admisión de un recurso, ya que requiere por su propia naturaleza una regulación por el Estado, que goza al respecto de cierto margen de apreciación (García Manibardo c. España [TEDH 2000, 73], núm. 38.695/1997, ap. 36, CEDH 2000-II). Sin embargo, las limitaciones aplicadas no deben restringir el acceso abierto al individuo de una manera o hasta el punto de que se vulnere el derecho en su propia sustancia. Además, no son conformes con el artículo 6.1 salvo si persiguen una finalidad legítima y si existe un vínculo razonable de proporcionalidad entre los medios empleados y la finalidad perseguida (ver, entre muchas otras, Edificaciones March Gallego, S.A. c. España, Sentencia de 19 de febrero de 1998 [TEDH 1998, 7], Repertorio de sentencias y decisiones 1998-I, ap. 34, y De la Fuente Ariza [TEDH 2007, 77], citada, ap. 22).

El Tribunal ha concluido en varias ocasiones de la aplicación por los tribunales internos de formalidades a respetar para interponer un recurso puede vulnerar el derecho de acceso a un Tribunal. Es asi cuando la interpretación, demasiado formalista, de la legalidad ordinaria hecha por un tribunal impide, de hecho, el examen a fondo del recurso ejercido por el interesado (Beles y otros c. República Checa [JUR 2002, 258.142], núm. 47.273/1999, ap. 69, CEDH 2002-IX, Zvolský y Zvolská [JUR 2003, 48435], citada, ap. 55).

\section{IMPOSIBILIDAD DE AGOTAR LA VÍA JUDICIAL PREVIA CONTRA EL REAL DECRETO 463/2020 Y DECRETOS POSTERIORES QUE LO PRORROGAN Y CARÁCTER AUTOAPLICATIVO DE LOS MISMOS}

Vamos a ver a continuación que, aplicando la doctrina del Tribunal Constitucional, el Tribunal Supremo considera que no cabe recurso contencioso administrativo contra el Real Decreto que declara el estado de alarma. 


\section{SUPERACIÓN DE LA TESIS NEGATIVA DE LA STC 83/2016}

1. La STC 83/2016 consideró acertada desde el punto de vista constitucional la resolución por la que el Tribunal Supremo resolvió que no entraba en el ámbito de la competencia de la jurisdicción contencioso-administrativa controlar vulneraciones de derechos fundamentales ocasionados por los reales decretos por los que se acordaba el estado de alarma y sus prórrogas. Ciertamente, respaldó al Tribunal supremo, no por el mismo argumento que había empleado el Tribunal Supremo, pero consideró constitucionalmente correcta la resolución adoptada por el Tribunal Supremo, por lo que cabría entender que no hay posibilidad de impugnar ante la jurisdicción ordinaria las disposiciones de un Real Decreto que declare el estado de alarma que ocasione una limitación de la libertad de reunión y de manifestación y de circulación. Concretamente, de la STC 83/2016 se podría deducir que no se puede impugnar ante la jurisdicción ordinaria el Real Decreto 463/2020 en el que declaró el estado de alarma y que contenía una limitación del derecho de los derechos a la reunión a la manifestación y a la circulación, como hemos visto que disponía su art. 7.

El art. 7 prohibía a todos los ciudadanos, sin necesidad de acto administrativo que lo desarrollara, la circulación por las vías de uso público salvo en los casos expresamente autorizados. Los cuerpos y fuerzas de seguridad del Estado velaban por el cumplimiento de esta previsión.

2. De la STC $83 / 2016$ se puede desprender que no se puede recurrir el art. 7 ante la jurisdicción ordinaria. El rango legal parecía imposibilitar su control por el Tribunal Supremo, aun cuando, si la disposición del Gobierno no hubiera tenido rango legal hubiera sido impugnable directamente ante el Tribunal Supremo. Es la declaración del valor de ley que le atribuyó la STC 83/2016 la que imposibilitaba acudir ante el Tribunal Supremo.

3. Pues bien, en este sentido, la Sección Cuarta de la Sala de lo contencioso-administrativo del Tribunal Supremo dictó Auto de 6 de mayo de 2020 inadmitiendo un recurso de anulación interpuesto contra los Reales Decretos 463/2020, de 14 de marzo, 476/2020, de 27 de marzo, y 487/2020, de 10 de abril. El ATS justifica su postura a lo largo del FD 2º, titulado «Extensión y límites de nuestra jurisdicción respecto de los Reales Decretos de declaración del estado de alarma», en el que cita la STC 83/2016 y el ATC 7/2012, y a lo largo del FD $4^{\circ}$, que lleva por título «La doctrina del Tribunal Constitucional», que recoge amplios fragmentos del ATC 7/2012 y de la STC 83/2016. El Tribunal Supremo, siguiendo la doctrina del Tribunal Constitucional según la cual los reales decretos que declaran el estado de alarma no eran disposiciones de carácter general de rango reglamentario, a las que se refiere el art. 1.1 de la Ley de jurisdicción contencioso-administrativa, concluyó que la Sala carecía 
de jurisdicción para conocer de un recurso contencioso-administrativo interpuesto por el cauce procesal de protección de los derechos fundamentales de la persona contra los Reales Decretos 463/2020, de 14 de marzo, 476/2020, de 27 de marzo, y 487/2020, de 10 de abril, que declararon el estado de alarma y las dos prórrogas posteriores.

4. Por tanto, el art. 7 del Real Decreto mencionado no sería recurrible ante la jurisdicción contencioso-administrativa y en tal sentido no se podría agotar vía judicial previa alguna antes de acudir al Tribunal Constitucional.

5. En este punto, creemos que el Tribunal Supremo ha hecho una interpretación de la jurisprudencia del Tribunal Constitucional y del ámbito de su propia jurisdicción que podría mejorarse trasladando al ámbito que nos ocupa las técnicas de control de los decretos legislativos. Es decir, entendiendo que el decreto que declara el estado de alarma, en la medida en que se extralimite de lo establecido en la LO 4/1981, de 1 de junio, de los estados de alarma, excepción y sitio, tiene rango de decreto y es susceptible de ser anulado por la jurisdicción contencioso-administrativa. Detengámonos en esta cuestión.

Tanto el Tribunal Supremo como el Tribunal Constitucional entienden que la eficacia de los decretos legislativos no es la misma que la de la ley ordinaria, sino que están sujetos a los límites que les ha impuesto la ley de delegación, respecto de la cual ocupan una posición de subordinación.

En efecto, la STC 205/1993, de 17 de junio, FJ 3, reconoce que:

La ley delegante habilita y al mismo tiempo limita el desarrollo de la actividad legislativa del Gobierno. La determinación del objeto, alcance, principios y criterios por parte de la Ley de Bases, circunscriben el campo de la delegación legislativa para asegurar que la delegación no se ejercite de modo divergente al objeto y a la finalidad que la determina. Mientras que el ejercicio directo de la función legislativa supone un margen de decisión sujeto sólo a mandatos constitucionales, el ejercicio delegado de la función legislativa supone que el Gobierno no sólo está sujeto a la Constitución, sino también a la delimitación precisa que la Ley de Bases ha de hacer sobre el objeto y alcance de la delegación y sobre los principios y criterios que han de seguirse en su ejercicio, los cuales al ser establecidos por la Ley de Bases permiten ser objeto del correspondiente debate parlamentario.

En consecuencia, los tribunales han aceptado la tesis que en su día formuló el profesor García de Enterría y que hoy recoge el art. 82.6 de la Constitución, tesis según la cual los decretos legislativos tienen rango de ley siempre que hayan respetado los límites impuestos por la ley de delegación. En la medida en que hayan desbordado la ley de delegación («exceso de delegación»), no tienen rango de ley, sino de reglamento, y por lo tanto son susceptibles de anulación por la jurisdicción contencioso-administrativa. 
Tanto el Tribunal Constitucional (SSTC 51/1982, de 19 de julio, y 47/1984, de 4 de abril) como los tribunales ordinarios aceptan esta tesis, que se deriva del art. 82.6 de nuestra Constitución y, en la actualidad, está recogida en la LJCA de 1998.

Concretamente, la STC 47/1984, de 4 de abril, FJ 3, declara que «el control de los excesos de la delegación legislativa corresponde no sólo al Tribunal Constitucional, sino también a la jurisdicción ordinaria. La competencia de los Tribunales ordinarios para enjuiciar la adecuación de los Decretos legislativos a las Leyes de delegación se deduce del art. 82.6 de la Constitución; [...] Por lo tanto, la nulidad de la norma originada por el exceso en la delegación — y la resultante inaplicación de la misma- pudo apreciarse en la instancia [...]». Así pues, los órganos judiciales contencioso administrativos pueden declarar la nulidad de las disposiciones de los decretos legislativos que excedan de la delegación (Rodríguez-Zapata, 2016: 202 y 203). Cita este autor las siguientes sentencias del Tribunal Supremo (Sala Tercera): Sentencia de la Sección tercera del 3 de noviembre de 1993 y Sentencias de la Sección segunda de 2 de julio de 1992 y del 6 de marzo de 1991.

6. Por lo demás, ya con referencia al estado de alarma declarado por el RD 1673/2010, de 4 de diciembre, se sostuvo en el ámbito doctrinal que se había realizado una interpretación forzada de la ley reguladora de los estados excepcionales (Vidal Prado y Delgado Ramos, 2012: 960).

\section{CARÁCTER NO FISCALIZABLE DE LAS ACTUACIONES DE LA ADMINISTRACIÓN}

1. A esto debemos añadir la imposibilidad real de cuestionar eficazmente la actuación de la Administración que a través de la potestad sancionadora y coactiva garantizaba el cumplimiento de las obligaciones impuestas por el Real Decreto. No es posible recurrir los actos de aplicación del Real Decreto que declara el estado de alarma ni por el procedimiento ordinario ni por el especial de protección de los derechos fundamentales. Veámoslo.

El Auto del Tribunal Supremo de 6 de mayo de 2020 sostenía que había posibilidad de recurrir los actos de aplicación de la declaración y de la prórroga. Concretamente, decía en el FD 5º, que lleva por título «Las consecuencias de la fuerza o valor de ley de los Reales Decretos no equivalen a una inmunidad frente al control jurisdiccional», que:

[...] la fiscalización por la jurisdicción constitucional de los Reales Decretos por los que se declara y se prorroga el estado de alarma no excluye el control jurisdiccional por los Tribunales ordinarios de los actos y disposiciones que se dicten en su aplicación durante la vigencia del estado de alarma. Asimismo, las personas afectadas 
podrán interponer recurso de amparo constitucional, previo agotamiento de la vía judicial ordinaria, contra los actos y disposiciones dictados en aplicación de aquellos Reales Decretos cuando se estimen lesivos de derechos fundamentales o libertades públicas susceptibles de protección a través de este proceso constitucional, facultad que le confiere el artículo 55.2 LOTC.

2. Ahora bien, esta posibilidad no era real y efectiva. En efecto, la actuación administrativa no podía ser controlada, porque la propia regulación del Real Decreto 463/2020, al suspender los términos e interrumpir los plazos para la tramitación de los procedimientos administrativos, imposibilitaba el agotamiento de la vía administrativa previa al control judicial. Así se desprendía, en efecto, de la disposición adicional tercera, apartado segundo.

La disposición adicional tercera decía lo siguiente:

1. Se suspenden términos y se interrumpen los plazos para la tramitación de los procedimientos de las entidades del sector público. El cómputo de los plazos se reanudará en el momento en que pierda vigencia el presente real decreto o, en su caso, las prórrogas del mismo.

2. La suspensión de términos y la interrupción de plazos se aplicará a todo el sector público definido en la Ley 39/2015, de 1 de octubre, del Procedimiento Administrativo Común de las Administraciones Públicas.

3. Además, aun admitiendo a efectos dialécticos que se pudiera agotar la vía administrativa previa, tampoco se podía intentar la tutela judicial, al quedar en suspenso también los términos e interrumpirse los plazos previstos en las leyes procesales para todos los órdenes jurisdiccionales, como se desprendía del apartado primero de la disposición adicional segunda. En efecto, según la disposición adicional segunda, relativa a la suspensión de plazos procesales, apartado primero: «Se suspenden términos y se suspenden e interrumpen los plazos previstos en las leyes procesales para todos los órdenes jurisdiccionales. El cómputo de los plazos se reanudará en el momento en que pierda vigencia el presente real decreto o, en su caso, las prórrogas del mismo».

4. Este precepto supone la oclusión formal de la vía judicial ordinaria. Y eso implicaba la inexistencia de procedimiento para impugnar las limitaciones de los derechos fundamentales derivadas del Real Decreto 463/2020 desde el 14 de marzo de 2020 hasta las cero horas del día 21 de junio de 2020, en que el estado de alarma finalizó de conformidad con el art. 2 del Real Decreto $555 / 2020$, de 5 de junio.

5. Esta imposibilidad estaba en contradicción evidente con el apdo. 1 del art. 3 de la Ley Orgánica 4/1981, de 1 de junio, de los estados de alarma, excepción y sitio, según el cual «los actos y disposiciones de la Administración 
Pública adoptados durante la vigencia de los estados de alarma, excepción y sitio serán impugnables en vía jurisdiccional de conformidad con lo dispuesto en las leyes». Aunque la Ley Orgánica 4/1981 no habilitaba al real decreto que declarara el estado de alarma para que pudiera suspender el control judicial de los actos y disposiciones adoptadas durante su vigencia, el real decreto lo suspendía al interrumpir los plazos de tramitación de los procedimientos administrativos y los plazos previstos en las leyes procesales para todos los órdenes jurisdiccionales. El control por la jurisdicción ordinaria se volvió impracticable tanto desde el punto de vista formal como material.

\section{PROCESO ESPECIAL DE PROTECCIÓN DE LOS DERECHOS FUNDAMENTALES}

1. Podría objetarse a lo que venimos diciendo (relativo a la inexistencia de mecanismo efectivo para impugnar las limitaciones de los derechos fundamentales) que la interrupción de plazos procesales no era aplicable al procedimiento para la protección de los derechos fundamentales de la persona previsto en los arts. 114 y siguientes de la Ley 29/1998, de 13 de julio, reguladora de la Jurisdicción Contencioso-administrativa. Por lo que hemos de completar nuestro análisis.

En efecto, según el apartado tres de la disposición adicional segunda del Real Decreto 463/2020, «en relación con el resto de órdenes jurisdiccionales la interrupción a la que se refiere el apartado primero no será de aplicación a los siguientes supuestos: a) El procedimiento para la protección de los derechos fundamentales de la persona previsto en los artículos 114 y siguientes de la Ley 29/1998, de 13 de julio, reguladora de la Jurisdicción Contencioso-administrativa, ni a la tramitación de las autorizaciones o ratificaciones judiciales previstas en el artículo 8.6 de la citada ley».

2. Sin embargo, esta objeción no tiene sentido si tenemos en cuenta los siguientes argumentos.

Por una parte, para acudir a la vía contencioso-administrativa es necesario agotar la vía administrativa previa frente a la actuación administrativa conforme al art. 25 de la Ley 29/1998, de 13 de julio, reguladora de la jurisdicción contencioso-administrativa, y esta posibilidad no existía por encontrarse suspendidos durante la vigencia del estado de alarma los plazos administrativos, salvo los procedimientos administrativos en los ámbitos de la afiliación, la liquidación y la cotización de la Seguridad Social y de los plazos tributarios, sujetos a normativa especial, ni afectará, en particular, a los plazos para la presentación de declaraciones y autoliquidaciones tributarias, todo ello de acuerdo con los apdos. 4 y 5 de la disposición adicional tercera del Real Decreto 463/2020. No se establecía excepción en relación 
a la interrupción de los plazos para la tramitación de procedimientos relativos a ámbitos de actuación distintos donde pudiera producirse vulneración de los derechos fundamentales. Es claro que si no existía un «acto de la Administración pública sujeto al Derecho administrativo» que pusiera fin a la vía administrativa no se podía acudir al proceso de protección de los derechos fundamentales de la persona, por más que formalmente no estuviera suspendido.

Por otra parte, en ausencia de un acto administrativo susceptible de ser objeto de un proceso, incluso si el Real Decreto 463/2020 y sus prórrogas fueran considerados norma con rango de ley, no cabría el planteamiento de cuestión de inconstitucionalidad.

3. En suma, no existiendo ningún mecanismo ni directo ni indirecto en manos del recurrente para poder impugnar la limitación de los derechos fundamentales derivada del Real Decreto 463/2020 y de las prórrogas subsiguientes, el real decreto reunía las características para poder ser susceptible de recurso de amparo ante el Tribunal Constitucional, toda vez que los ciudadanos se encontraban privados de la posibilidad real y efectiva de cualquier otro tipo de recurso frente a las limitaciones de sus derechos fundamentales. En caso contrario, el Real Decreto 463/2020, en conjunción con la interpretación de la jurisprudencia constitucional sobre el estado de alarma, habría creado un espacio exento de control real y efectivo de tutela de los derechos fundamentales.

La conjunción de la suspensión de los plazos administrativos y procesales establecida por el Real Decreto 463/2020 y el rango legal atribuido a la norma por el Tribunal Constitucional imposibilitaba la impugnación administrativa y judicial del Real Decreto 463/2020 o de los actos de aplicación del mismo.

\section{RECURSO DE INCONSTITUCIONALIDAD Y CUESTIÓN DE INCONSTITUCIONALIDAD}

1. Por otra parte, aun partiendo de la hipótesis de que el decreto de alarma fuera un acto de naturaleza parlamentaria (Álvarez Vélez, 2017: 337), el recurso de inconstitucionalidad y la cuestión de inconstitucionalidad tampoco se presentan como instrumentos idóneos para el control de las posibles vulneraciones de derechos fundamentales mientras el estado de alarma estuviera vigente, sino solo con posterioridad. De hecho, hay un recurso de inconstitucionalidad admitido sobre la materia (Garrido López, 2021). Recordemos que nos referimos al estado de alarma declarado por el RD 463/2020, no a la declaración del estado de alarma en general, que, si se considera que tiene naturaleza de ley, será recurrible en inconstitucionalidad (García Cuadrado, 1994: 106). 
2. El Acuerdo del Pleno del Tribunal Constitucional de 16 de marzo de 2020 por el que se suspendieron los plazos para realizar cualquier actuación procesal y administrativa ante el Tribunal Constitucional coadyuvó a que el control de los reales decretos no se pudiera llevar a efecto hasta que se dejara sin efecto el estado de alarma. Esto concierne al recurso de inconstitucionalidad y a la cuestión de inconstitucionalidad, que eran los cauces de control a los cabía entender que remitía la STC 83/2016, FJ 11.

3. Por lo que se refiere al recurso de inconstitucionalidad, en un primer análisis parece presentar características idóneas para servir como mecanismo de garantía de los derechos constitucionales, aunque sea de manera indirecta. El tiempo de respuesta previsto legalmente lo posibilitaba, ya que el art. 34 LOTC establece que admitida a trámite la demanda, la personación y la formulación de alegaciones deberán hacerse en el plazo de 15 días, transcurrido el cual el Tribunal dictará sentencia en el de 10, salvo que, mediante resolución motivada, el propio Tribunal estime necesario un plazo más amplio que, en ningún caso, pueda exceder de 30 días. Ahora bien, si tenemos en cuenta que el plazo de presentación del recurso de inconstitucionalidad conforme al art. 33.1 LOTC es de tres meses y sobre todo que el Acuerdo del Pleno del Tribunal Constitucional adoptado el 16 de marzo de 2020 de suspender, durante la vigencia del Real Decreto 463/2020 y sus prórrogas, los plazos para realizar cualesquiera actuaciones procesales y administrativas ante el Tribunal Constitucional, a lo que se añade el tiempo de respuesta medio del Tribunal Constitucional, se concluye que el recurso de inconstitucionalidad no podría tramitarse en un plazo razonable a efectos de salvaguardar los derechos afectados por el Real Decreto 463/2020.

Además, el Tribunal Constitucional, en el ATC 90/2010, de 14 de julio, interpretó que solo se permite el aplazamiento de la vigencia de la norma cuando se trate de leyes autonómicas que impugne el Gobierno de la Nación invocando el art. 161.2 de la Constitución, por lo que no es posible acordar la suspensión de otras normas con rango de ley del Estado, por más que se solicite.

4. Por lo que se refiere a la cuestión de inconstitucionalidad, podría pensarse que esta era una vía idónea para garantizar la tutela de los derechos fundamentales vulnerados por el Real Decreto 463/2020, toda vez que contra la actuación sancionadora de la Administración en cumplimiento de las obligaciones derivadas del real decreto y sus prórrogas se podía solicitar tutela judicial una vez agotada la vía administrativa. Ahora bien, de nuevo nos encontramos con que la suspensión de los plazos administrativos imposibilitaba que pudiera darse lugar a proceso alguno de protección de derechos fundamentales frente a la limitación de la libertad de circulación, de residencia o de reunión. A lo que ha de añadirse que cualquier cuestión de inconstitucionalidad que 
se hubiera planteado ante el Tribunal Constitucional, si tenemos en cuenta la suspensión de los plazos procesales acordada por el Pleno del Tribunal Constitucional en su Acuerdo de 16 de marzo de 2020, y la suspensión de los plazos ante la jurisdicción ordinaria dispuesta por el real decreto de declaración del estado de alarma y sus prórrogas, no hubiera podido tramitarse hasta que el estado de alarma hubiera concluido. Todo esto sin tener en cuenta que los periodos de tiempo necesarios de hecho para la tramitación y planteamiento de la cuestión de inconstitucionalidad y para admisión, tramitación y resolución por el Tribunal Constitucional harían imposible una respuesta efectiva antes de que se hubieran consumado las eventuales vulneraciones de derechos fundamentales.

\section{RECAPITULACIÓN Y CONCLUSIONES}

1. En el presente trabajo se intenta dilucidar si el ciudadano en nuestro país ha dispuesto de un recurso real y efectivo para discutir la constitucionalidad o legalidad del Real Decreto 463/2020, de 14 de marzo, por el que se declara el estado de alarma para la gestión de la situación de crisis sanitaria ocasionada por el COVID-19. A estos efectos, nos centramos en el precepto limitador contenido en el art. 7 del Real Decreto 463/2020, el cual dispuso que, durante la vigencia del estado de alarma, «las personas únicamente podrán circular por las vías o espacios de uso público para la realización de las siguientes actividades [...]».

2. El real decreto de declaración del estado de alarma de 2020 mencionado es una disposición del Gobierno de carácter general, contra la que cabe recurso ante el orden jurisdiccional contencioso-administrativo, recurso que puede ser directo (en la medida en que incluya preceptos autoaplicativos) e indirecto (es decir, dirigido contra los actos aplicativos, pero fundamentado en la ilegalidad o en la inconstitucionalidad del decreto). Y contra la eventual inadmisión o desestimación del recurso contencioso administrativo, en calidad de vía judicial previa, podrá presentarse recurso de amparo ante el Tribunal Constitucional.

3. Sin embargo, la jurisprudencia del Tribunal Supremo y del Tribunal Constitucional parece no entenderlo así, y hemos visto que su doctrina podría derivar en la imposibilidad de controlar jurídicamente la declaración del estado de alarma. Obviamente, el principio conforme al cual nuestro Estado es un Estado de derecho y el derecho del ciudadano a un recurso efectivo suponen un obstáculo a una lectura de esa jurisprudencia que conduzca a ese resultado y ponen de relieve la eventual necesidad de matizarlas o rectificarlas. En efecto, aplicando la doctrina del Tribunal Constitucional, el Tribunal Supremo ha 
llegado a considerar, sorprendentemente, que no cabe recurso contencioso administrativo contra el real decreto que declara el estado de alarma.

4. Ahora bien, en rigor, no existe jurisprudencia constitucional acerca de la recurribilidad en amparo de la declaración del estado de alarma si tenemos en cuenta que la afirmación del FJ 11 de la STC 83/2016 según la cual frente a tales reales decretos solo caben los procesos constitucionales previstos para el control de constitucionalidad de las leyes no se integra en la ratio decidendi de la sentencia. No hay ninguna sentencia ni auto del Tribunal Constitucional que haya afrontado una pretensión de amparo deducida contra el real decreto que declara el estado de alarma. Cabe precisar que el ATC 7/2012 lo que excluyó fue que el art. 42 LOTC estableciera la posibilidad de interponer recurso de amparo frente a un acuerdo del Parlamento por el que se autorizaba la prórroga del estado de alarma — no frente a la declaración del estado de alarma en sí-, basándose en que se trataba de una disposición de naturaleza parlamentaria y con valor de ley.

Por lo que se refiere a la STC 83/2016, lo que desestimó fue la alegación de vulneración del acceso a la jurisdicción de una decisión del Tribunal Supremo (recurso por la vía del art. 44 LOTC) de no controlar reales decretos por los que se acordaba el estado de alarma y sus prórrogas al considerar que desbordaban el ámbito que delimita su jurisdicción. El objeto del recurso no era el decreto en sí.

5. Aun aceptando, a efectos dialécticos, tras la STC 83/2016, que los reales decretos que declaran el estado de alarma tengan rango de ley, ello no obstaría para que sean recurribles en amparo ante el Tribunal Constitucional. La doctrina general aplicable a los reglamentos en cuanto normas generales, según la cual no solo pueden generar lesión a particulares a través de los actos de aplicación, se puede trasladar a este ámbito.

Cuando las disposiciones del gobierno son «autoaplicativas», esto es, cuando pueden irrogar una lesión de un derecho fundamental sin necesidad de que medien actos de aplicación, podemos derivar de la jurisprudencia del Tribunal Constitucional que cabe la impugnación directa de los mismos. En la única ocasión en que este tema se ha planteado en un proceso ante el Tribunal Constitucional, este último no excluyó la posibilidad de impugnación directa, si bien en aquel caso la desestimó por entender que la norma impugnada no era autoaplicativa. Se trata del ATC 291/1997, de 22 de julio, en el que se resolvió acerca de un recurso de amparo planteado directamente contra determinados preceptos de un decreto ley, y en el que se dijo que: «[...] en el ámbito del recurso de amparo [...] podrá procederse al enjuiciamiento de normas cuando por su mera existencia o entrada en vigor se cause la lesión concreta y actual del derecho fundamental (STC 167/1987, fundamento jurídico 2)» (ATC 291/1997, FJ 2). 
6. Es una exigencia del Estado de derecho y del derecho a recurso efectivo entender que, a la vista de la regulación del estado de alarma que realizó el Real Decreto 463/2020 y los que acordaron la prórroga del mismo, la posible vulneración de derechos fundamentales de modo directo por los mencionados reales decretos, como los derechos fundamentales afectados por su art. 7, hubiera debido ser susceptible de ser planteada en un recurso de amparo ante el Tribunal Constitucional.

7. Por otra parte, esas mismas exigencias podrían llevar al Tribunal Supremo a matizar su postura respecto de la irrecurribilidad de los decretos que declaran el estado de alarma y a entender que, aun partiendo de que sean actos del Gobierno con rango de ley, los mismos, en la medida que excedan el marco de la Ley reguladora de los estados de alarma, excepción y sitio, tienen naturaleza reglamentaria y no legal y en consecuencia serían susceptibles de revisión por la jurisdicción contencioso administrativa.

\section{Bibliografía}

Aba, A. M. (2011). El estado de alarma en España. Teoría y Realidad Constitucional. Asamblea, (28), 313-341. Disponible en: https://doi.org/10.5944/ trc.28.2011.6961.

Álvarez, M. I. (2016). Sistema de fuentes del Derecho y estado de alarma: la STC 83/2016, de 28 de abril. Asamblea, 34, 325-337.

Arnaldo, E. (2020). «Salus populi est lex, sed lex superior est constitutio»: el ejercicio del derecho de manifestación en el estado de alarma. Diario La Ley, 9637.

Cotino, L. (2021). La (in)constitucionalidad de las restricciones y suspensión de la libertad de circulación por el confinamiento frente a la Covid. Excepcionalidady Derecho: el estado de alarma en España (capitulos). Zaragoza: Fundación Manuel Giménez Abad. Disponible en: https://www.fundacionmgimenezabad.es/es/excepcionalidad-y-derecho-el-estado-de-alarma-en-espana-capitulos.

Cruz, P. (1981). El nuevo derecho de excepción: Ley Orgánica 4/1981, de 1 de junio. Revista Española de Derecho Constitucional, 2, 93-128.

- (1984). Estados excepcionales y suspensión de garantías. Madrid: Tecnos.

- (2004). Normalidad y excepción. Revista Española de Derecho Constitucional, $71,187-200$.

Díaz, F. J. (2021). Desactivando conceptos constitucionales: la suspensión de derechos y los estados excepcionales. Excepcionalidad y Derecho: el estado de alarma en España (capitulos). Zaragoza: Fundación Manuel Giménez Abad. Disponible en: https://www.fundacionmgimenezabad.es/es/excepcionalidad-y-derecho-el-estado-de-alarma-en-espana-capitulos. 
Escobar, G. (2021). Los derechos humanos en estados excepcionales y el concepto de suspensión de derechos fundamentales. Revista de Derecho Político, 110, 113152. Disponible en: https://doi.org/10.5944/rdp.110.2021.30330.

Fernández, F. (1981). La ley orgánica de los estados de alarma, excepción y sitio. Revista de Derecho Político, 11, 83-116. Disponible en: https://doi.org/10.5944/ rdp.11.1981.8119.

García, A. M. (1994). El estado de alarma y su ambigua naturaleza. Cuadernos Constitucionales de la Cátedra Fabrique Furió Ceriol, 8, 75-106.

- (1999). Aproximación a una teoría de los actos constitucionales. Revista de Derecho Politico, 46, 59-95.

Garrido, C. (2021). Las limitaciones como Derecho del Derecho constitucional de excepción. Excepcionalidad y Derecho: el estado de alarma en España (capitulos). Zaragoza: Fundación Manuel Giménez Abad. Disponible en: https:/www. fundacionmgimenezabad.es/es/excepcionalidad-y-derecho-el-estado-de-alarma-en-espana-capitulos.

Goig, J. M. (2009a). La defensa política de la Constitución: Constitución y estados excepcionales: un estudio de derecho constitucional comparado (I). Revista de Derecho, 4, 263-296.

- (2009b). La defensa política de la Constitución: Constitución y estados excepcionales: un estudio de derecho constitucional comparado (II). Revista de Derecho, 5, 211-251.

Gómez, I. (2021). ¿Limitación o suspensión? Una teoría de los límites a los derechos fundamentales para evaluar la adopción de estados excepcionales. Excepcionalidad y Derecho: el estado de alarma en España (capitulos). Zaragoza: Fundación Manuel Giménez Abad. Disponible en: https://www.fundacionmgimenezabad. es/es/excepcionalidad-y-derecho-el-estado-de-alarma-en-espana-capitulos.

Lafuente, J. M. (1989). Los estados de alarma, excepción y sitio (I). Revista de Derecho Politico, 30, 25-54. Disponible en: https://doi.org/10.5944/rdp.30.1989.8427.

- (1990). Los estados de alarma, excepción y sitio (II). Revista de Derecho Politico, 31, 27-67. Disponible en: https://doi.org/10.5944/rdp.31.1990.8441.

Muñoz, S. (2020). El poder y la peste de 2020. El Cronista del Estado social y Democrático de Derecho, 90, 114-129.

Navas, A. (1997). Los estados excepcionales y su posible control por el Tribunal constitucional. Revista de la Facultad de Derecho de la Universidad Complutense, 87, 141-169.

Presno, M. A. (2021). El derecho de reunión durante el estado de alarma por Covid-19. Excepcionalidad y Derecho: el estado de alarma en España (capitulos). Zaragoza: Fundación Manuel Giménez Abad. Disponible en: https:/www. fundacionmgimenezabad.es/es/excepcionalidad-y-derecho-el-estado-de-alarma-en-espana-capitulos.

Requejo, J. L. (coord.) (2001). Comentarios a la Ley Orgánica del Tribunal Constitucional. Madrid: Tribunal Constitucional. 
Rodríguez, J. M. (1981). Los ámbitos exentos del control del Tribunal Constitucional español. En VV.AA. El Tribunal Constitucional (pp. 2308-2325). Madrid: Instituto de Estudios Fiscales.

Rodríguez, J. (2016). Teoría y práctica del derecho constitucional. Madrid: Tecnos.

Torres, I. (2009). Art. 116: Los estados excepcionales. Comentarios a la Constitución española: XXX aniversario (pp. 1814-1820.). Las Rozas (Madrid): Fundación Wolters Kluwer.

Vidal Prado, C. y Delgado Ramos, D. (2011). Algunas consideraciones sobre la declaración del estado de alarma y su prórroga. Revista Española de Derecho Constitucional, 92, 243-265.

Vidal Prado, C. y Delgado Ramos, D. (2012). Alcune considerazioni sulla dichiarazione dello stato di allarme e sulla prorroga nellórdinamento spagnolo. Diritto pubblico comparato ed europeo, 3, 947-961.

Villar, G. (2018). Comentario a la STC 83/2016: con motivo de la naturaleza de los decretos del gobierno que declaran el estado de alarma. Revista General de Derecho Administrativo, 48, 11. 